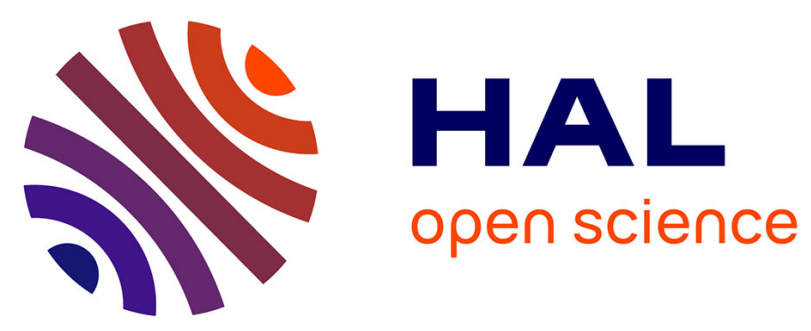

\title{
Multimorbidity Is Associated with Preclinical Alzheimer's Disease Neuroimaging Biomarkers
}

Aline Mendes, Sophie Tézenas Du Montcel, Marcel Levy, Anne Bertrand, Marie-Odile Habert, Hugo Bertin, Bruno Dubois, Stéphane Epelbaum

\section{To cite this version:}

Aline Mendes, Sophie Tézenas Du Montcel, Marcel Levy, Anne Bertrand, Marie-Odile Habert, et al.. Multimorbidity Is Associated with Preclinical Alzheimer's Disease Neuroimaging Biomarkers. Dementia and Geriatric Cognitive Disorders, 2018, 45 (5-6), pp.272-281. 10.1159/000489007 . hal01958870

\section{HAL Id: hal-01958870 \\ https://hal.sorbonne-universite.fr/hal-01958870}

Submitted on 19 Dec 2018

HAL is a multi-disciplinary open access archive for the deposit and dissemination of scientific research documents, whether they are published or not. The documents may come from teaching and research institutions in France or abroad, or from public or private research centers.
L'archive ouverte pluridisciplinaire HAL, est destinée au dépôt et à la diffusion de documents scientifiques de niveau recherche, publiés ou non, émanant des établissements d'enseignement et de recherche français ou étrangers, des laboratoires publics ou privés. 
1 Multimorbidity is associated with preclinical Alzheimer's disease

2 neuroimaging biomarkers

3

$4 \quad$ Running Head

$5 \quad$ Multimorbidity and cognition in older adults

6

$7 \quad$ Aline Mendes ${ }^{1,2}$, MD, Sophie Tezenas du Montcel ${ }^{3,4}, \mathrm{MD}, \mathrm{PhD}$, Marcel Levy ${ }^{2}$

$8 \mathrm{MD}$, Anne Bertrand MD ${ }^{5,6,7}, \mathrm{PhD}$, Marie Odile Habert $\mathrm{MD}^{8}$, Hugo Bertin ${ }^{8}$,

9 Bruno Dubois $\mathrm{MD}^{2}$, Stéphane Epelbaum ${ }^{2,5,7} \mathrm{MD}, \mathrm{PhD}$.

10

11 INSIGHT-PreAD study group

$12{ }^{1}$ Department of internal medicine, rehabilitation and geriatrics

13 Geneva University Hospitals, Switzerland.

$14{ }^{2}$ Institut de la mémoire et de la maladie d'Alzheimer, Département de

15 neurologie, Hôpital de la Pitié Salpêtrière, 47 Bd de l'Hôpital, 75013, Paris,

16 France.

$17{ }^{3}$ Sorbonne Universités, Université Pierre et Marie Curie (UPMC) Univ Paris 18 06, UMR S 1136, INSERM U 1136, Institut Pierre Louis d'Epidémiologie et de

19 Santé Publique, F-75013, Paris, France.

$20{ }^{4}$ AP-HP, Biostatistics Unit, Groupe Hospitalier Pitié-Salpêtrière, F-75013,

21 Paris, France.

$22{ }^{5}$ Sorbonne Universités, UPMC Univ Paris 06, Inserm, CNRS, Institut du

23 cerveau et la moelle (ICM), AP-HP - Hôpital Pitié-Salpêtrière, Boulevard de 24 I'hôpital, F-75013, Paris, France. 
$26{ }^{6}$ AP-HP, Hôpital de la Pitié-Salpêtrière, Department of Neuroradiology, F-

27 75013, Paris, France

$28{ }^{7}$ Inria Paris, Aramis project-team, 75013, Paris, France.

$29{ }^{8}$ Nuclear Medicine Department, University Hospital Pitié Salpêtrière, 75013

30 Paris, France.

31 Title character count: 89

32 Number of references: 35

33 Number of tables: 3

34 Number of figures: 1

35 Word count abstract: 200

36 Word count paper: 2396

37

38 Corresponding author: Aline Mendes, aline.mendes@hcuge.ch

39 Geneva University Hospitals

40 Departement of Internal Medicine, Rehabilitation and Geriatrics

41 Chemin du Pont-Bochet 3, 1226 Thônex

42 tel: +41793144344

43

44 Key-words: Alzheimer's disease, multimorbidity, neuroimaging biomarkers, 45 amyloid, neurodegeneration.

46

47

48

49

50 


\section{Abstract}

52 Background: Identifying comorbidities that influence preclinical Alzheimer's

53 disease $(A D)$ can give some insight about the $A D$ early stages trajectories to

54 allow new treatment venues and to guide public health systems to prevent

55 subsequent dementia.

56 Objective: To examine the association of multimorbidity with AD

57 neuroimaging markers in cognitively normal older adults.

58 Methods: Cross-sectional design. Data regarding 14 comorbidities were

59 obtained for all 318 adults aged 70 to 85 years, recruited from the community

60 to an ongoing prospective monocentric cohort. They underwent standardized

61 neuropsychological and neuroimaging assessment with automated methods

62 that measured hippocampal volumes, WMH volumes, FDG-PET SUV in AD

63 signature regions and amyloid PET SUV ratios. Linear regression was used to

64 assess the association of multimorbidity with AD neuroimaging biomarkers.

65 Results: Multimorbidity is significantly associated to lower hippocampal

66 volumes $(-0.03 \pm 0.01 ; P=.012 ; R 2=.017)$ and lower FDG-PET SUV $(-0.027$

$67 \pm 0.009 ; P=.005 ; R 2=.022$ ), with no association with amyloid deposition

$68 \quad(0.001 \pm 0.007 ; P=.884 ; R 2=.0001)$. Taken individually, obesity and

69 excessive alcohol use are associated with lower FDG-PET values.

70 Surprisingly, obstructive sleep apnea and mood disorders are related to lower

71 Amyloid-PET SUVr.

72 Conclusions: Multimorbidity is associated with preclinical AD imaging

73 markers of neurodegeneration, but not with amyloid. 


\section{Introduction}

Several acquired comorbidities have been described to increase the risk of developing dementia or Alzheimer's disease (AD). ${ }^{1}$ Most of them are conditions that are modifiable with treatment, such as hypertension, dyslipidemia or diabetes. ${ }^{2}$ The co-occurrence of multiple chronic conditions ( $\geq 2$ diseases) characterizes multimorbidity, an entity which prevalence rises with age ${ }^{3}$, affecting more than a half of the older adults population. Multimorbidity has been associated with adverse health outcomes as mild cognitive impairment, ${ }^{4}$ diminished quality of life, functional limitation, frailty and mortality. ${ }^{5}$ Many of these chronic conditions commonly observed in multimorbidity are also the same established risk factors of AD. Moreover, they can directly impact brain neurogenesis by different underlying mechanisms, influencing for example the size of hippocampus towards lower volumes throughout life. ${ }^{6}$

This study aims to examine whether different AD neuroimaging biomarkers of neurodegeneration and amyloid burden relate to comorbidities individually, as well as to their accumulation termed "multimorbidity" in cognitively normal older adults. In the scope of recent failures of targeted drug trials against $A D,{ }^{7}$ the identification of treatable conditions that raise the risk of preclinical $A D$ might 1) play a role in future trials as enrichment factors at inclusion; 2) give some mechanistic insight about the early stage of $A D$ to allow new treatment venues and; 3) guide public health systems to prevent subsequent dementia.

\section{Methods}

\section{Study population}


99 The INSIGHT-PreAD is an ongoing prospective monocentric cohort with the

100 objective to determine factors that increase the risk of progression of

101 cognitively normal older adults to clinical AD. INSIGHT-PreAD enrolled

102 participants aged 70 to 85 years, with a subjective cognitive decline (SCD)

103 and no objective cognitive disorders defined by a mini-mental state

104 examination score (MMSE) $\geq 27$ and total recall score in the free and cued

105 selective reminding test (FCSRT) $\geq 41 .{ }^{8}$ Exclusion criteria included clinical

106 dementia rating scale $(\mathrm{CDR})>0,{ }^{9}$ visual and auditory functions insufficient for

107 neuropsychological testing, the existence of a known neurological disease,

108 recent stroke and illiteracy.

109 The study was approved by the local ethical committee (ANSM 130134B-31)

110 and all participants signed a written informed consent.

\section{Clinical data}

112 Demographic data were obtained at baseline and a comorbidity profile was

113 established based on self-reported diagnosis during the standardized clinical

114 follow-up. The presence of fourteen chronic conditions was assessed:

115 hypertension, dyslipidemia, diabetes mellitus, atrial fibrillation, heart failure,

116 chronic kidney disease, obstructive sleep apnea (OSA), active or past

117 smoking, unhealthy alcohol consumption, prior head trauma, obesity, vitamin

118 B12 deficiency, depression and post-traumatic stress disorder (PTSD).

119 Diagnoses were validated by a physician (AM), according to standardized

120 criteria from the international classification of diseases (ICD-10). Data

121 regarding chronic kidney failure was not available for 23 subjects.

122 Regarding mood disorders, we considered the diagnosis present for both

123 early and late-onset episodes, as well as recurrent disorder. All head trauma 
124 episodes were recorded, independent of severity. Excessive alcohol

125 consumption was defined according to the diagnostic and statistical manual of

126 mental disorders (DSM-5) criteria.

127 Neuroimaging assessment

128 Hippocampal volumetry

129 All participants underwent an MRI at baseline in the same Siemens

130 Magnetom Verio 3-T scan. The MRI acquisition protocol is described in the 131 supplementary material.

132 The hippocampal segmentation was performed using a fully automated in-

133 house developed method, based on simultaneous region deformation driven

134 by both anatomical and probabilistic priors. ${ }^{10}$ Anatomical information was

135 derived from local anatomical patterns that are stable in controls and AD

136 patients, around landmarks automatically detected during the deformation.

137 Probabilistic information was derived from an atlas built from the registration

138 of manually segmented hippocampus from 16 young healthy subjects.

139 Initialization was obtained from global information and deformation is

140 constrained by local anatomical and probabilistic information.

141 Volumes were normalized by the total intracranial volume (TIV). ${ }^{11}$

142 White Matter Hyperintensities (WMH) volumetry

143 Automated volumetry of $\mathrm{WMH}$ was obtained from all participants using the

144 WMH Automated Segmentation Algorithm (WHASA) method and expressed

145 in $\mathrm{cm}^{3}$. WHASA relies on increased contrast between $\mathrm{WMH}$ and surrounding

146 tissues by extracting tissue information from T1 images, registering it to the

147 FLAIR image and correcting for intensity inhomogeneities. ${ }^{12}$ Non-linear

148 diffusion framework enables then to enhance the contrast of $\mathrm{WMH}$ on the 
149 FLAIR image and obtain a piecewise constant image.

150 Positron Emission Tomography studies with 18 Fluoro Deoxyglucose

151 (FDG-PET) and with amyloid ligand 18F-Florbetapir

152 - FDG-PET and florbetapir images acquisition - Brain amyloid PET scans

153 were acquired 50 minutes after injection of $370 \mathrm{MBq}(10 \mathrm{mCi})$ of $18 \mathrm{~F}$ -

154 Florbetapir. Brain FDG-PET scans were obtained 30 minutes after injection of $1552 \mathrm{MBq} / \mathrm{kg}$ of 2-deoxy-2-(18F)fluoro-D-glucose. All acquisitions were performed 156 in a single session on a Philips Gemini GXL scanner and consisted of $3 \times 5$

157 minutes frames with a voxel size of $2 \times 2 \times 2 \mathrm{~mm}^{3}$. Images were then

158 reconstructed using iterative LOR-RAMLA algorithm. Lastly, frames were

159 realigned, averaged and quality-checked by a dedicated neuroimaging

160 specialist team (CATI for "Centre pour l'Acquisition et le Traitement des

161 Images", http://cati-neuroimaging.com/).

162 - PET images processing - The CATI developed a pipeline allowing

163 quantifying radiotracer uptake in the grey matter of untransformed PET

164 images, with high throughput and a step-by-step quality check. The aim was

165 to reduce quantification biases related to spatial normalization, co-registration

166 and partial volume effect (PVE). MRI 3D T1-weighted images were

167 segmented and spatially normalized into the MNI space using the VBM8

168 package implemented in SPM8. ${ }^{13}$ Deformation fields, grey and white matter

169 masks were generated and further used to define ROIs. Structural MRI

170 images were co-registered to PET images using SPM8 with visual inspection

171 to detect any co-registration errors. Using inverse deformation fields and

172 matrix transformation, composite cortical ROls and a reference region were

173 placed in the individual native PET space. After correcting for PVE with the 
174 RBV-sGTM method, ${ }^{14}$ parametric PET images were created for each

175 individual, by dividing each voxel with the mean activity extracted from the 176 reference region.

177 - PET variables - Metabolic indexes were calculated in ROls involving AD

178 specific regions such as right and left precuneus, posterior cingulate cortex,

179 associative parietal and temporal cortex, hippocampus, as well as ROls in the

180 frontal and occipital cortex. ${ }^{15}$ The reference region was the pons. For amyloid

181 PET images, standard uptake value ratios (SUVr) were calculated by

182 averaging the mean activity of cortical ROls: both left and right precuneus,

183 cingulum posterior, cingulum anterior, parietal, temporal and orbitofrontal

184 cortex. The reference region was a combination of whole cerebellum and

185 pons regions. ${ }^{16}$

186 Statistical analysis

187 Descriptive data of the population is expressed as number of cases and 188 proportions for categorical variables and as means and standard deviations

189 for continuous variables. Differences between men and women were

190 assessed by Fisher's exact test or t-test if variables were categorical or

191 continuous, respectively.

192 The associations among the accumulation of comorbidities and their effect as

193 individual conditions with the AD neuroimaging biomarkers were assessed by

194 linear regression methods. For this purpose, hippocampal volumes, metabolic

195 indexes and amyloid-PET SUVr were analyzed as continuous variables in our 196 models.

197 We predetermined five possible confounding factors for adjustments in the 198 multivariate analysis: age, sex, educational level, ApoE4 status and WMH 
199

200

201

202

203

204 Results were considered significant at $\mathrm{P}<0.05$ and all statistical analyses were 205 217 prevalence.

volumes. We performed linear regression univariate analysis to evaluate their association to neuroimaging variables Variables presenting statistically significant associations were used as adjustment factors in the multivariate linear regression model for comorbidity, applied to their respective neuroimaging biomarker. performed using SAS software (version 9.4; SAS Institute, Cary).

\section{Results}

\section{Population characteristics}

The cohort of 318 cognitively normal subjects was composed by 204 (64.2\%) women, with a global mean age of 76 years (SD: 3$)$. They have a high mean sociocultural level (6, SD: 2 ), on a scale from 1 (no formal education) to 8 (at least two years post high school graduation). Hypertension, dyslipidemia, mood disorders and chronic kidney failure were the most common observed comorbidities and $70 \%$ of participants had at least 2 chronic conditions (table 1). Mood disorders were more prevalent in women, whereas hypertension, heart failure, obstructive sleep apnea and tobacco use were significantly more prevalent in men. There were no differences regarding APOE4 allele

\section{Adjustment factors and neuroimaging biomarkers}

Age influenced the 3 biomarkers studied, while female gender was associated with higher normalized hippocampal volumes and FDG PET, with no differences in amyloid-PET SUVr (table 2). Higher comorbidity burden observed in men can partly explain these differences. 
223 While ApoE4 status was not associated with FDG-PET indexes, a trend

224 toward significance was observed in the association of positive ApoE4 status

225 and lower hippocampal volumes. Interestingly, WMH was not associated with

226 hippocampal volumes or FDG-PET indexes, however higher WMH volumes

227 were significantly associated to higher SUVr in amyloid-PET (figure 1).

228 Multimorbidity and neuroimaging biomarkers

229 The increasing number of comorbidities was significantly associated with

230 lower hippocampal volumes $\left(-0.03 \pm 0.01 ; P=.012 ; \mathrm{R}^{2}=.017\right)$ as well as with

231 lower SUV $\left(-0.027 \pm 0.009 ; P=.005 ; R^{2}=.022\right)$ in FDG-PET. In the other

232 hand, we did not observe any association between comorbidities

233 accumulation and SUVr in amyloid PET $\left(0.001 \pm 0.007 ; P=0.884 ; R^{2}=.0001\right)$.

234 After adjustment for possible confounding factors, the association remained

235 statistically significant only for FDG-PET SUV $\left(-0.02 \pm 0.01 ; P=.038 ; R^{2}=.07\right)$.

236 Both obesity and excessive alcohol use were associated with lower

237 metabolism in FDG-PET, in univariate and multivariate models. Moreover,

238 smoking presented a statically significant association with lower hippocampal

239 volumes, but no significant association was observed after adjustment for

240 possible confounding factors (table 3).

241 Increased amyloid-PET SUVr was associated with the presence of

242 dyslipidemia in the univariate linear regression model $(0.048 \pm 0.022 ; P=.029$;

$\left.243 \mathrm{R}^{2}=.047\right)$. Surprisingly, OSA and mood disorders were inversely associated

244 with amyloid-PET SUVr, remaining statistically significant after adjustment for

245 possible confounding factors (table 3).

246 Discussion 
247 In this study with 318 cognitively normal older adults, we observed that the

248 accumulation of multiple chronic conditions, i.e. multimorbidity, is associated

249 with neuroimaging markers of AD neurodegeneration, but not with amyloid 250 deposition.

251 Some of the multiple chronic conditions explored in our study were singularly

252 associated to lower hippocampal volumes and lower metabolism in AD-

253 specific brain regions. The lower metabolism in FDG-PET AD signature

254 regions was independent of ApoE4 status. These results are in agreement 255 with a previous study regarding 1449 cognitively normal subjects, in which

256 investigators observed an association of multimorbidity with FDG-PET

257 hypometabolism and abnormal AD signature cortical thickness, whereas

258 these were unrelated to amyloid. ${ }^{17}$ Our study demonstrates comparable

259 results with a different spectrum of comorbidities, adding information

260 regarding the association with hippocampal atrophy, not yet assessed.

261 Besides that, by using a linear regression statistical approach, we could

262 establish associations without determining normal/abnormal cut-off values in

263 neuroimaging variables, showing that the association of comorbidities with

264 neurodegeneration may be part of a continuum. ${ }^{18,19}$ Interactions among

265 vascular risk factors, frequently observed as comorbidities in older adults are

266 probably implicated in this pathophysiology. ${ }^{20,21}$ Multimorbidity has been

267 recognized as an entity by itself, exceeding the simple co-existence of

268 multiple chronic conditions. ${ }^{22}$ It has been demonstrated that their interactions

269 transcend a merely additive effect, presenting a more complex synergism

270 regarding vascular burden for example, but also other pathophysiological

271 processes such as inflammation and oxidative stress. ${ }^{23}$ Our hypothesis is that 
272 different diseases clusters create different illness burden and may impact in a

273 unique manner neurodegeneration. ${ }^{24}$ Therefore, the type, number and

274 severity of comorbidities may modulate the rate of atrophy and metabolism

275 decline, being at least one important variable in a complex model of factors

276 determining the extent of preclinical AD stage.

277 Surprisingly, we did not observe a relation between lower hippocampal

278 volumes and vascular risk factors, classically related to a negative impact on

279 hippocampus neurogenesis. This may be explained by our small sample size.

280 We observed that active or past smoking was associated with lower

281 hippocampal volumes. It has been demonstrated that chronic cigarette

282 smoking may negatively impact cognition, including memory, due to oxidative

283 stress-induced lesions. ${ }^{25}$ We found that a chronic excessive alcohol use was

284 associated with lower metabolism in FDG-PET. Alcohol consumption seems

285 to influence hippocampal neurogenesis as well as brain metabolism. ${ }^{26}$

286 Intoxication states are associated with a switch in metabolism patterns,

287 increasing acetate metabolism and reducing glucose use, as it was

288 demonstrated in FDG-PET studies. ${ }^{27}$ It is not clear whether these effects may

289 be transitory or permanent in the path towards neurodegeneration.

290 In this study, obesity was related to lower metabolism in FDG-PET, but not to

291 hippocampal atrophy. Obesity seems to be implicated in neurodegeneration,

292 increasing the risk of cognitive impairment in late life and has been shown to

293 be associated with decreased brain volumes. ${ }^{28,29}$

294 In this study, OSA and mood disorders were associated with lower amyloid-

295 PET SUVr. However, there is evidence that both comorbidities may be

296 actually associated with increased amyloid deposition. OSA leads to recurrent 
sleep fragmentation and hypoxia, which upregulates the expression of the amyloid precursor protein (APP), diminishing $A \beta$ clearance from the brain. ${ }^{30}$ In animal models, chronic hypoxia enhanced amyloid plaques generation with a significant decline in memory. ${ }^{31}$ Depression is not only an $A D$ risk factor, but it can also be an initial phenotype of $A D .^{32}$ There is evidence relating mood disorders to amyloid deposition, mainly from cross-sectional studies, showing that subjects with major depression have lower CSF AB42 and higher amyloid deposition in PET studies. ${ }^{33,34}$ The discrepancies with our data may be a result of the lack of information available regarding the depression episode (early-life, late-late or recurrent), as well as the severity of the disease and possible treatments implemented for both comorbidities.

As recent data from previous cross-sectional studies, we also found an association between higher $\mathrm{WMH}$ volumes and amyloid deposition. ${ }^{35} \mathrm{WMH}$ are highly prevalent and clearly related to vascular risk factors in older adults, however the possible causal relationship between amyloid and WMH needs further exploration in longitudinal studies. WMH could accelerate amyloid deposition, but amyloid may also affect WMH burden, independently of vascular risk factors treatment.

This study has strengths, but also some limitations. The cross-sectional analyses do not allow us to infer temporality associations between comorbidities and neuroimaging biomarkers. Also, there is a possible selection bias regarding the participants of INSIGHT PreAD who are mostly highly educated. This could influence the prevalence of comorbidities. The main strength of this study lies in its standardized multimodal clinical and neuroimaging acquisition protocols and its monocentric nature, allowing for 
322 optimal homogeneity of the cohort. A future longitudinal analysis in

323 multimorbidity may help to understand the progression of neurodegeneration

324 and amyloid deposition along with possible causality associations. Various

325 comorbidities may be targeted with adequate treatment, raising the question

326 of how their multimodal assessment and therapies during the early and late

327 adult lifespan could impact pre-clinical AD trajectories. 
328

329

330

331 the IHU-A-ICM.

332 Aline Mendes reports no disclosures.

333 Sophie Tezenas du Montcel reports no disclosures.

334 Marcel Levy reports no disclosures.

335 Marie-Odile Habert has received honoraria as a speaker or consultant for

336 AVID-LILLY, GE Healthcare, and PIRAMAL companies.

337 Stéphane Epelbaum has received honoraria as a speaker or consultant for

338 ELI-LILLY and GE Healthcare.

339 Bruno Dubois has received honoraria as a speaker or consultant for ELI-

340 LILLY and GE Healthcare.

341 Anne Bertrand reports no disclosures.

343 Author contributions:

344 Aline Mendes - takes full responsability for the data. Contribution to the study

345 concept and design, data acquisition, analysis, interpretation and manuscript

346 elaboration

347 Stéphane Epelbaum - study supervision (concept and design), interpretation

348 and critical revision of the manuscript

349 Marie-Odile Habert - PET data acquisition and analysis, critical revision of the

350 manuscript

351 Hugo Bertin - PET data acquisition and analysis

352 Sophie Tezenas du Montcel - data analysis 
353 Marcel Levy - subjects' follow up, critical revision of the manuscript

354 Bruno Dubois - Interpretation and critical revision of the manuscript

355 Anne Bertrand - MRI data acquisition and analysis

356

357 References

358 1. Norton S, Matthews FE, Barnes DE, Yaffe K, Brayne C. Potential for 359 primary prevention of Alzheimer's disease: an analysis of population$360 \quad$ based data. Lancet Neurol. 2014;13:788-794.

361 2. Whitmer RA, Sidney S, Selby J, Johnston SC, Yaffe K. Midlife 362 cardiovascular risk factors and risk of dementia in late life. Neurology. $363 \quad 2005 ; 64: 277-281$.

364 3. Marengoni A, Rizzuto D, Wang H-X, Winblad B, Fratiglioni L. Patterns of 365 chronic multimorbidity in the elderly population. J. Am. Geriatr. Soc. $366 \quad 2009 ; 57: 225-230$.

367 4. Vassilaki M, Aakre JA, Cha RH, Kremers WK, St Sauver JL, Mielke MM, 368 et al. Multimorbidity and Risk of Mild Cognitive Impairment. J. Am. Geriatr. 369 Soc. $2015 ; 63: 1783-1790$.

370 5. Smith SM, Wallace E, O'Dowd T, Fortin M. Interventions for improving 371 outcomes in patients with multimorbidity in primary care and community 372 settings. Cochrane Database Syst. Rev. 2016;3:CD006560.

373 6. Fotuhi M, Do D, Jack C. Modifiable factors that alter the size of the 374 hippocampus with ageing. Nat. Rev. Neurol. 2012;8:189-202. 
375 7. Doody RS, Thomas RG, Farlow M, Iwatsubo T, Vellas B, Joffe S, et al.

376 Phase 3 trials of solanezumab for mild-to-moderate Alzheimer's disease.

377 N. Engl. J. Med. 2014;370:311-321.

378 8. Folstein MF, Folstein SE, McHugh PR. "Mini-mental state". A practical

379 method for grading the cognitive state of patients for the clinician. J.

$380 \quad$ Psychiatr. Res. 1975;12:189-198.

381 9. Hughes CP, Berg L, Danziger WL, Coben LA, Martin RL. A new clinical

382 scale for the staging of dementia. Br. J. Psychiatry J. Ment. Sci.

$383 \quad 1982 ; 140: 566-572$.

384 10. Chupin M, Gerardin E, Cuingnet R, Boutet C, Lemieux L, Lehericy S, et

385 al. Fully automatic hippocampus segmentation and classification in

386 Alzheimer's disease and mild cognitive impairment applied on data from

$387 \quad$ ADNI. Hippocampus. 2009;19:579-587.

388 11. Colliot $\mathrm{O}$, Chetelat $\mathrm{G}$, Chupin M, Desgranges B, Magnin B, Benali $\mathrm{H}$, et al.

389 Discrimination between Alzheimer disease, mild cognitive impairment,

390 and normal aging by using automated segmentation of the hippocampus.

391 Radiology. 2008;248:194-201.

392 12. Samaille T, Fillon L, Cuingnet R, Jouvent E, Chabriat $H$, Dormont $D$, et al.

393 Contrast-based fully automatic segmentation of white matter

394 hyperintensities: method and validation. PloS One. 2012;7:e48953.

395 13. VBM at Structural Brain Mapping Group [Internet]. [cited 2017 Jan

396 7];Available from: http://dbm.neuro.uni-jena.de/vbm/ 
14. Thomas BA, Erlandsson K, Modat M, Thurfjell L, Vandenberghe R, Ourselin S, et al. The importance of appropriate partial volume correction for PET quantification in Alzheimer's disease. Eur. J. Nucl. Med. Mol. Imaging. 2011;38:1104-1119.

15. Jack CRJ, Knopman DS, Weigand SD, Wiste HJ, Vemuri $P$, Lowe V, et al. An operational approach to National Institute on Aging-Alzheimer's Association criteria for preclinical Alzheimer disease. Ann. Neurol. $2012 ; 71: 765-775$.

16. Brendel M, Hogenauer M, Delker A, Sauerbeck J, Bartenstein P, Seibyl J, et al. Improved longitudinal [(18)F]-AV45 amyloid PET by white matter reference and VOI-based partial volume effect correction. Neurolmage. 2015;108:450-459.

17. Vassilaki M, Aakre JA, Mielke MM, Geda YE, Kremers WK, Alhurani RE, et al. Multimorbidity and neuroimaging biomarkers among cognitively normal persons. Neurology. 2016;86:2077-2084.

18. Roberts RO, Knopman DS, Cha RH, Mielke MM, Pankratz VS, Boeve BF, et al. Diabetes and elevated hemoglobin A1c levels are associated with brain hypometabolism but not amyloid accumulation. J. Nucl. Med. Off. Publ. Soc. Nucl. Med. 2014;55:759-764.

19. Yaffe K, Kanaya A, Lindquist K, Simonsick EM, Harris T, Shorr RI, et al. The metabolic syndrome, inflammation, and risk of cognitive decline. JAMA. 2004;292:2237-2242. 
20. Bangen KJ, Nation DA, Delano-Wood L, Weissberger GH, Hansen LA, Galasko DR, et al. Aggregate effects of vascular risk factors on cerebrovascular changes in autopsy-confirmed Alzheimer's disease. Alzheimers Dement. J. Alzheimers Assoc. 2015;11:394-403.e1.

21. Wiseman RM, Saxby BK, Burton EJ, Barber R, Ford GA, O'Brien JT. Hippocampal atrophy, whole brain volume, and white matter lesions in older hypertensive subjects. Neurology. 2004;63:1892-1897.

22. Fabbri E, Zoli M, Gonzalez-Freire M, Salive ME, Studenski SA, Ferrucci L. Aging and Multimorbidity: New Tasks, Priorities, and Frontiers for Integrated Gerontological and Clinical Research. J. Am. Med. Dir. Assoc. 2015;16:640-647.

23. Marengoni A, Angleman S, Melis R, Mangialasche F, Karp A, Garmen A, et al. Aging with multimorbidity: a systematic review of the literature. Ageing Res. Rev. 2011;10:430-439.

24. Hsu H-C. Trajectories of multimorbidity and impacts on successful aging. Exp. Gerontol. 2015;66:32-38.

25. Gazdzinski S, Durazzo TC, Yeh P-H, Hardin D, Banys P, Meyerhoff DJ. Chronic cigarette smoking modulates injury and short-term recovery of the medial temporal lobe in alcoholics. Psychiatry Res. 2008;162:133145.

26. Lee J, Im S-J, Lee S-G, Stadlin A, Son J-W, Shin C-J, et al. Volume of hippocampal subfields in patients with alcohol dependence. Psychiatry Res. 2016;258:16-22. 
27. Volkow ND, Wang G-J, Shokri Kojori E, Fowler JS, Benveniste H, Tomasi D. Alcohol decreases baseline brain glucose metabolism more in heavy drinkers than controls but has no effect on stimulation-induced metabolic increases. J. Neurosci. Off. J. Soc. Neurosci. 2015;35:32483255.

28. Whitmer RA, Gustafson DR, Barrett-Connor E, Haan MN, Gunderson EP, Yaffe K. Central obesity and increased risk of dementia more than three decades later. Neurology. 2008;71:1057-1064.

29. Albanese E, Davis B, Jonsson PV, Chang M, Aspelund T, Garcia M, et al. Overweight and Obesity in Midlife and Brain Structure and Dementia 26 Years Later: The AGES-Reykjavik Study. Am. J. Epidemiol. $2015 ; 181: 672-679$.

30. Austin BP, Nair VA, Meier TB, Xu G, Rowley HA, Carlsson CM, et al. Effects of hypoperfusion in Alzheimer's disease. J. Alzheimers Dis. JAD. 2011;26 Suppl 3:123-133.

31. Guglielmotto M, Aragno M, Autelli R, Giliberto L, Novo E, Colombatto S, et al. The up-regulation of BACE1 mediated by hypoxia and ischemic injury: role of oxidative stress and HIF1alpha. J. Neurochem. 2009;108:1045-1056.

32. Dotson VM, Davatzikos C, Kraut MA, Resnick SM. Depressive symptoms and brain volumes in older adults: a longitudinal magnetic resonance imaging study. J. Psychiatry Neurosci. JPN. 2009;34:367-375. 
464 33. Pomara N, Bruno D, Osorio RS, Reichert C, Nierenberg J, Sarreal AS, et al. State-dependent alterations in cerebrospinal fluid Abeta42 levels in cognitively intact elderly with late-life major depression. Neuroreport. 2016;27:1068-1071.

34. Wu K-Y, Hsiao I-T, Chen C-S, Chen C-H, Hsieh C-J, Wai Y-Y, et al. Increased brain amyloid deposition in patients with a lifetime history of major depression: evidenced on 18F-florbetapir (AV-45/Amyvid) positron emission tomography. Eur. J. Nucl. Med. Mol. Imaging. 2014;41:714-722.

35. Scott JA, Braskie MN, Tosun D, Maillard P, Thompson PM, Weiner M, et al. Cerebral amyloid is associated with greater white-matter hyperintensity accrual in cognitively normal older adults. Neurobiol. Aging. 2016;48:48-52. 
477 Table 1. Characteristics of the study population at baseline.

478

\begin{tabular}{|l|r|r|r|r|}
\hline \multicolumn{1}{|c|}{ Characteristics } & Women $\mathbf{n = 2 0 4}$ & Men $\mathbf{n = 1 1 4}$ & \multicolumn{1}{c|}{ p value } & \multicolumn{1}{c|}{ Total $\mathbf{n = 3 1 8}$} \\
\hline Age, mean (SD) & $76.0(3.3)$ & $76.2(3.9)$ & 0.654 & $76.1(3.5)$ \\
\hline Education level, mean (SD) & $5.9(2.0)$ & $6.7(2.0)$ & 0.001 & $6.2(2.1)$ \\
\hline APOE4, $\mathrm{n}(\%)$ & $41(20.1)$ & $18(15.8)$ & 0.371 & $59(18.6)$ \\
\hline HTA, $\mathrm{n}(\%)$ & $77(37.8)$ & $60(52.6)$ & 0.013 & $137(43.1)$ \\
\hline Atrial Fibrillation, $\mathrm{n}(\%)$ & $18(8.8)$ & $11(9.6)$ & 0.84 & $29(9.1)$ \\
\hline Heart Failure, $\mathrm{n}(\%)$ & $17(8.3)$ & $19(16.7)$ & 0.028 & $36(11.3)$ \\
\hline Dyslipidemia, $\mathrm{n}(\%)$ & $82(40.2)$ & $54(47.4)$ & 0.238 & $136(42.8)$ \\
\hline Diabetes, $\mathrm{n}(\%)$ & $10(4.9)$ & $6(5.3)$ & $>0.99$ & $16(5)$ \\
\hline Obstructive sleep apnea, $\mathrm{n}(\%)$ & $7(3.4)$ & $13(11.4)$ & 0.007 & $20(6.3)$ \\
\hline Head trauma, $\mathrm{n}(\%)$ & $20(9.8)$ & $6(5.3)$ & 0.201 & $26(8.2)$ \\
\hline Mood disorders, $\mathrm{n}(\%)$ & $71(34.8)$ & $17(14.9)$ & $<0.0001$ & $88(27.7)$ \\
\hline B12 deficiency, $\mathrm{n}(\%)$ & $3(1.5)$ & $2(1.8)$ & $>0.99$ & $5(1.6)$ \\
\hline PTSD, $\mathrm{n}$ (\%) & 0 & $1(0.9)$ & 0.358 & $1(0.3)$ \\
\hline Unhealthy alcohol use, $\mathrm{n}(\%)$ & $17(8.3)$ & $14(12.3)$ & 0.324 & $31(9.7)$ \\
\hline Smoked ever, $\mathrm{n}(\%)$ & $55(27)$ & $69(60.5)$ & $<0.0001$ & $124(39)$ \\
\hline Current smoking, $\mathrm{n}(\%)$ & $12(5.9)$ & $9(7.9)$ & 0.489 & $21(6.6)$ \\
\hline BMI, mean (SD) & $25.0(3.8)$ & $25.5(2.9)$ & 0.236 & $25.2(3.5)$ \\
\hline Obesity, $\mathrm{n}(\%)$ & $20(9.8)$ & $6(5.3)$ & 0.201 & $26(8.2)$ \\
\hline Chronic kidney disease, $\mathrm{n}(\%)$ & $41(21.7)$ & $23(21.7)$ & $>0.99$ & $64(21.7)$ \\
\hline Comorbidities total, mean (SD) & $2.2(1.4)$ & $2.7(1.5)$ & 0.004 & $2.4(1.5)$ \\
\hline Number of comorbidities, $\mathrm{n}(\%)$ & & & 0.011 & \\
\hline 0-1 & $71(34.8)$ & $24(21.1)$ & & $95(29.9)$ \\
\hline$\geq 2$ & $133(65.2)$ & $90(78.9)$ & & $223(70.1)$ \\
\hline
\end{tabular}

479

480 Abbreviations: HTA = Arterial hypertension; PTSD = Post-traumatic stress

481 disorder; $\mathrm{BMI}=$ Body mass index .

482 Fisher's exact test categorical variables or t-test for continuous variables.

483 Level of education is assessed by a scale from 1 (no formal education) to 8

484 (at least two years post high school graduation). 
486 Table 2. Assessment of the association of potential adjustment factors for the

487 multivariate comorbidity model with AD neuroimaging biomarkers.

488

\begin{tabular}{|c|c|c|c|c|c|c|}
\hline \multirow{2}{*}{$\begin{array}{l}\text { Adjustment } \\
\text { factors }\end{array}$} & $\begin{array}{c}\text { Hippocampal } \\
\text { volume }\end{array}$ & \multirow{2}{*}{$\begin{array}{c}P \\
\text { value }\end{array}$} & FDG-PET SUV & \multirow{2}{*}{$\begin{array}{c}P \\
\text { value }\end{array}$} & $\begin{array}{c}\text { Amyloid-PET } \\
\text { SUVr }\end{array}$ & \multirow{2}{*}{$\begin{array}{c}P \\
\text { value }\end{array}$} \\
\hline & $n=318$ & & $n=314$ & & $n=318$ & \\
\hline Age & $-0.023 \pm 0.005$ & $<.001$ & $-0.01 \pm 0.004$ & 0.013 & $0.006 \pm 0.003$ & 0.043 \\
\hline Women & $0.169 \pm 0.035$ & $<.001$ & $0.112 \pm 0.03$ & $<.001$ & $-0.026 \pm 0.022$ & 0.235 \\
\hline $\begin{array}{l}\text { Level of } \\
\text { education }\end{array}$ & $0.001 \pm 0.008$ & 0.927 & $-0.012 \pm 0.007$ & 0.073 & $-0.001 \pm 0.005$ & 0.793 \\
\hline $\begin{array}{l}\text { APOE4 } \\
\text { status }\end{array}$ & $-0.081 \pm 0.042$ & 0.053 & $-0.007 \pm 0.036$ & 0.837 & $0.123 \pm 0.026$ & $<.001$ \\
\hline $\begin{array}{l}\text { WMH } \\
\text { volume }\end{array}$ & $-0.002 \pm 0.001$ & 0.2 & $0.001 \pm 0.001$ & 0.365 & $0.003 \pm 0.001$ & 0.0002 \\
\hline
\end{tabular}

489

490 Abbreviations: $\mathrm{WMH}=$ white matter hyperintensities.

491 Linear regression univariate analysis.

492 Level of education is assessed by a scale from 1 (no formal education) to 8

493 (at least two years post high school graduation). 
494 Table 3. Associations of multimorbidity and comorbidities individually with AD

495 neuroimaging biomarkers.

496

\begin{tabular}{|c|c|c|c|}
\hline & Hippocampal volume & FDG-PET SUV & Amyloid-PET SUVr \\
\hline & $n=318$ & $n=314$ & $n=318$ \\
\hline \multirow{3}{*}{$\begin{array}{l}\text { Comorbidity } \\
\text { number }\end{array}$} & $-0.03 \pm 0.01$ & $-0.027 \pm 0.009$ & $0.001 \pm 0.007$ \\
\hline & $P=0.012$ & $P=0.005$ & $P=0.884$ \\
\hline & $R^{2}=0.017$ & $R^{2}=0.022$ & $\mathrm{R}^{2}=0.0001$ \\
\hline $\begin{array}{c}\text { Adjustment } \\
\text { factors }\end{array}$ & $\begin{array}{c}\text { Age, Sex, APOE4 } \\
\text { status }\end{array}$ & Age, Sex & ApoE4, Age, WMH \\
\hline \multirow{3}{*}{$\begin{array}{c}\text { Comorbidity } \\
\text { number after } \\
\text { adjustment }\end{array}$} & $-0.017 \pm 0.01$ & $-0.02 \pm 0.01$ & $0.0004 \pm 0.007$ \\
\hline & $P=0.125$ & $P=0.038$ & $P=0.96$ \\
\hline & $\mathrm{R}^{2}=0.17$ & $\mathrm{R}^{2}=0.07$ & $R^{2}=0.122$ \\
\hline \multirow{14}{*}{$\begin{array}{l}\text { Comorbidities } \\
\text { individually }\end{array}$} & $\mathrm{n}=295$ & $\mathrm{n}=292$ & $\mathrm{n}=295$ \\
\hline & Tobbaco use & Obesity & Obstructive Sleep Apnea \\
\hline & $-0.081 \pm 0.035$ & $-0.108 \pm 0.051$ & $-0.095 \pm 0.043$ \\
\hline & $P=0.022$ & $P=0.037$ & $P=0.028$ \\
\hline & $R^{2}=0.018$ & $R^{2}=0.041$ & $\mathrm{R}^{2}=0.016$ \\
\hline & & Excessive alcohol use & Mood disorders \\
\hline & & $-0.138 \pm 0.049$ & $-0.051 \pm 0.024$ \\
\hline & & $P=0.005$ & $P=0.035$ \\
\hline & & $R^{2}=0.027$ & $R^{2}=0.031$ \\
\hline & & & \\
\hline & & & Dyslipidemia \\
\hline & & & $0.048 \pm 0.022$ \\
\hline & & & $P=0.029$ \\
\hline & & & $R^{2}=0.047$ \\
\hline $\begin{array}{c}\text { Adjustment } \\
\text { factors }\end{array}$ & $\begin{array}{c}\text { Age, Sex, APOE4 } \\
\text { status }\end{array}$ & Age, Sex & Age, APOE4 status, WMH \\
\hline \multirow{13}{*}{$\begin{array}{l}\text { Comorbidities } \\
\text { individually } \\
\text { after } \\
\text { adjustments }\end{array}$} & Tobbaco use & Obesity & Obstructive Sleep Apnea \\
\hline & $-0.059 \pm 0.035$ & $-0.142 \pm 0.05$ & $-0.084 \pm 0.04$ \\
\hline & $P=0.094$ & $P=0.005$ & $P=0.039$ \\
\hline & $R^{2}=0.169$ & & \\
\hline & & Excessive alcohol use & Mood disorders \\
\hline & & $-0.112 \pm 0.045$ & $-0.053 \pm 0.022$ \\
\hline & & $P=0.014$ & $P=0.018$ \\
\hline & & & \\
\hline & & $R^{2}=0.094$ & \\
\hline & & & Dyslipidemia \\
\hline & & & $0.022 \pm 0.02$ \\
\hline & & & $P=0.29$ \\
\hline & & & $R^{2}=0.148$ \\
\hline
\end{tabular}


497 Linear regression models in univariate and multivariate analysis; results 498 expressed as Parameter Estimate \pm Standard Error. As for the adjustment 499 factors, significant associations in univariate analysis realized for 5 pre500 determined factors (age, sex, educational level, ApoE4 status and WMH 501 volumes) were incorporated in each model of AD neuroimaging biomarker.

502 Individual comorbidities not shown in the table did not have a statistically 503 significant association $(P<0.05)$ in the univariate model. Abbreviations: WMH $504=$ White matter hyperintensities . 
506 Figure 1. Association of WMH volumes with amyloid-PET SUVR.

507

$508{ }^{a}$ Linear regression model, $0.003 \pm 0.0008 ; P<0.001 ; R^{2}=0.12$.

$509{ }^{\mathrm{b}}$ The association remains statistically significant after exclusion of this outlier

510 participant from the analysis.

511 Abbreviations: $\mathrm{WMH}=$ White matter hyperintensities . 